
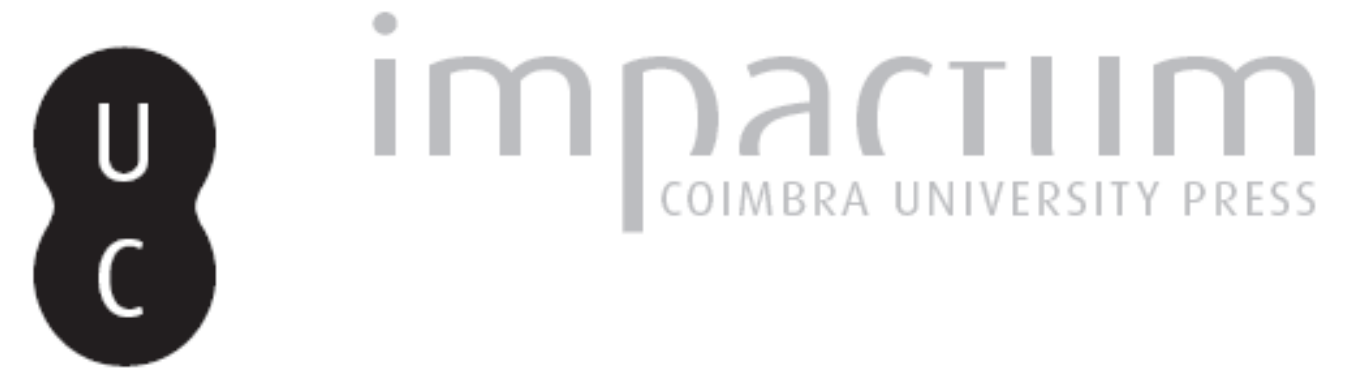

\title{
As saudações do além entre os romanos
}

\section{Autor(es): $\quad$ Ferreira, Ana Paula}

Publicado por: Imprensa da Universidade de Coimbra

URL persistente:

URl:http://hdl.handle.net/10316.2/45444

DOI:

DOI:https://dx.doi.org/10.14195/1647-8657_35_5

Accessed : $\quad$ 26-Apr-2023 12:44:18

A navegação consulta e descarregamento dos títulos inseridos nas Bibliotecas Digitais UC Digitalis, UC Pombalina e UC Impactum, pressupõem a aceitação plena e sem reservas dos Termos e Condições de Uso destas Bibliotecas Digitais, disponíveis em https://digitalis.uc.pt/pt-pt/termos.

Conforme exposto nos referidos Termos e Condições de Uso, o descarregamento de títulos de acesso restrito requer uma licença válida de autorização devendo o utilizador aceder ao(s) documento(s) a partir de um endereço de IP da instituição detentora da supramencionada licença.

Ao utilizador é apenas permitido o descarregamento para uso pessoal, pelo que o emprego do(s) título(s) descarregado(s) para outro fim, designadamente comercial, carece de autorização do respetivo autor ou editor da obra.

Na medida em que todas as obras da UC Digitalis se encontram protegidas pelo Código do Direito de Autor e Direitos Conexos e demais legislação aplicável, toda a cópia, parcial ou total, deste documento, nos casos em que é legalmente admitida, deverá conter ou fazer-se acompanhar por este aviso. 
UNIVERSIDADE DE COIMBRA

FACULDADE DE LETRAS

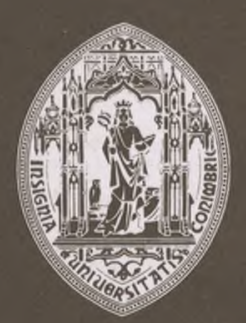

\section{CONIMBRIGA}

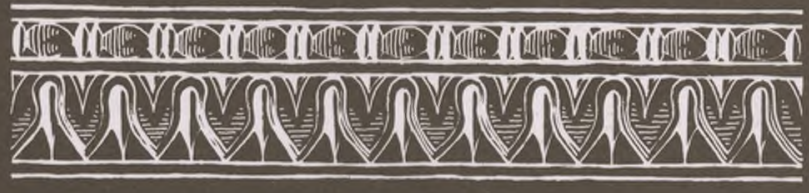

VOLUME XXXV - 1996 
ANA PAUla FERREIRA

Licenciada em Arqueologia

AS SAUDAÇÕES DO ALÉM ENTRE OS ROMANOS

"Conimbriga" XXXV (1996) p. 107-127

ReSUmo: A autora, restringindo-se geograficamente à Península Ibérica, proce-

deu à pesquisa e recolha de todos os epitáfios romanos com saudações.

Foi seu objectivo relacioná-los com a aculturação e a ocorrência em áreas urbanas ou rurais.

ReSUMÉ: L'Auteur a étudié les épitaphes romaines de la Péninsule Ibérique qui présentent des salutations et les a mis en rapport avec l'acculturation et leur ocurrence en moyen urbain ou rural.

Conimbriga, 35 (1996) 107-127 
(Página deixada propositadamente em branco) 


\section{AS SAUDAÇÕES DO ALÉM ENTRE OS ROMANOS}

\section{Ave! Salve!}

Estas expressões são fórmulas de saudação que os Romanos repetiriam todos os dias vezes sem conta e que, por isso, poderíamos dizer que não têm nenhum interesse em particular. Mas, quando se verifica que estas e outras formas de saudação aparecem em epitáfios latinos, logo nos despertam interesse e então quando nos apercebemos que, algumas vezes, a saudação parte do defunto para os vivos a curiosidade invade-nos. O defunto saúda-nos, insiste em partilhar o mundo dos vivos. É estranho. Será estranho para nós que vivemos a uma distância temporal de milénios. E, para os contemporâneos qual o significado desta saudação? A repugnância pela morte?, Para apaziguar o terror dos mortos aos vivos?, Ou resultará de uma moda característica de uma determinada época?

A questão da morte e da sepultura ocupa entre os Romanos um lugar considerável. $O$ morto era abrigado num monumento onde se colocava um epitáfio que, como actualmente, lhe perpetuava a memória. Era, também, a última oportunidade de prestar homenagem ao defunto pelo que, por vezes, manifesta uma grande ternura por parte dos sobreviventes, a qual está patente, por exemplo, no epitáfio que Nebullo dedica à sua companheira de escravidão Marta (MAZZOLANI 1991 XXIV): Flevi, Martha, tuos extremo tempore casus ossaque composui. Pignus amoris habes ("Chorei, Marta, o doloroso fim dos teus dias e enterrei os teus ossos. Aceita esta prova do meu amor"). Quanta emoção não provoca ainda hoje esta mensagem, passados que são quase dois mil anos !... 
Estes epitáfios são, assim, uma fonte imprescindível para o estudo das mentalidades, nomeadamente para a forma como os Romanos encaravam a morte. Esta não é, assim, uma questão actual, pois desde sempre o Homem se preocupou com ela e, portanto, também os Romanos não podiam deixar de manifestar o mesmo sentimento.

Para estes, vita bonum est et vita malum, mors neutrum habet horum (*) (“A vida é boa, a vida é má. A morte não é uma coisa nem outra"). Realmente, a morte não é boa nem má; a morte é o desconhecido e, como tal, gera medo, é terrível. Assim a considera um pobre pescador $\left(^{2}\right)$, com quase 90 anos, que passada "uma vida de privações (...), sem filhos, e além disso, coxo e com a vista obscurecida", queria viver, porque “a luz era agradável e morrer é terrível e de fugir”. E mais terrível era para quem morria cedo, pois, como refere Térpsion( $\left(^{3}\right)$, "as coisas deviam seguir a sua ordem natural: primeiro, o mais velho, e depois dele quem na idade esteja também a seguir. E não serem de forma alguma, revolucionadas, nem viver o velhorro (...) ao passo que os rapazinhos mais belos e cheios de força são quem morre. Isto é como os rios correrem para as nascentes".

Apesar de terrível, a morte é a única certeza do homem, e dela também tinham consciência os Romanos, como se verifica no epitáfio de Valério Avito (Fouilles II 71), de Conímbriga, que nos previne de que mors omnibus in stat ("A ameaça da morte paira sobre todos nós"). Exemplos desta advertência há-os em todos os tempos. Desde a Idade Média - em que um defunto nos diz que "o que fomos, é-lo tu agora, o que somos, sê-lo-ás"( $\left.{ }^{4}\right)$ - ao nosso século:

"Ó tu que me vês aqui;

Assim feia com sobejo;

Vigia, olha por ti;

Tu te vês, qual eu me vi;

Ver-te-has qual eu me vejo", (5)

(') Assim começa o epitáfio de Tícia Lucila, de 14 anos, da Tunísia (MAZZOLANI 1991 LXXVII).

(2) Personagem da obra de Luciano, Diálogo dos Mortos (XXVII pp. 92-93).

(3) Ibidem (VI p. 30).

$\left(^{4}\right)$ Epitáfio de um indivíduo falecido entre 1130-38. A inscrição encontra-se no claustro de S. Vitor em Paris (ARIÉs 1977 p. 258).

(5) Epitáfio que se encontrava no antigo cemitério de Cascais, hoje patente no Museu dos Condes de Castro Guimarães daquela vila. (informação do Prof. Doutor José d'Encamaçâ).

Conímbriga, 35 (1996) 107-127 
Entre os Romanos, tão viva era a certeza da morte como a crença na sobrevivência do homem na sepultura. Esta era já a crença dos Romanos primitivos, pois como refere Vergilio (Eneida Livro III p. 53) acerca dos funerais de Polidoro: "encerramos a sua alma no sepulcro". Acreditavam mesmo que os mortos eram dignificados e equiparados às divindades, começando a viver entre estas. Assim, as almas dos mortos, na sua qualidade de divinas, recebiam o nome comum de Dii Manes (VASCONCELOS 1913 p. 395). Acreditavam ainda que estas não se mantinham encerradas nos túmulos, abandonando-os em certos dias do ano( $\left.{ }^{6}\right)$ e, nestes, os vivos tentavam apaziguá-las para que lhes fossem favoráveis. E é por isso que prestam culto às sepulturas, que as consagram aos deuses, que enumeram as virtudes do defunto e fazem o voto de que "a terra lhes seja leve", e por isso também viviam bem longe deles (CAESSA p. 21).

Relacionado com esta crença está o desejo de respeito pelo túmulo. Daí aparecerem nos epitáfios latinos afirmações em defesa da inviolabilidade do sepulcro - como Huic monumento dolus malus abesto ("Que o mal permaneça afastado deste monumento") - ou mesmo ameaças aos violadores - como no interessante epitáfio de Mevia Sofia (MAzzolani 1991 LII) que no final previne o transeunte de que ita post obitum sit tibe [sic] terra levis, ut tu hic nihil laeseris, aut si quis laeseris, nec superis comprobetur nec inferi recipiant, et sit ei terra gravis, ("depois da morte que a terra te seja leve se não fizeres nenhum ultraje a esta sepultura: se qualquer um a profanar, não seja aceite no céu, nem recebido nos infernos e a terra pese sobre ele!). Também com o desejo de não profanação da sepultura se colocava, muitas vezes, nos epitáfios, a área da sepultura com o sentido de afirmação de um valor individual (cf. RODRIGUEZ NEILA 1991).

A ideia, ainda actual, de Inferno para tormento dos maus e de Céu para a felicidade dos bons, estava presente entre os Romanos (VASCONCELOS 1913 p. 392). O Inferno, segundo o barqueiro Caronte, é o lugar "das sombras, do sono e da noite soporífera" (Eneida Livro VI p. 131). O barqueiro Caronte é "um barqueiro horrendo" que "guardadas águas e os rios (...) de terrível sujidade, cuja barba abundante, branca e mal tratada, lhe cai do queixo (...)" (Eneida Livro

(6) Havia mesmo circuntâncias em que os mortos voltavam oficialmente, como nos cortejos que acompanhavam os defuntos à pira, figurados por actores disfarçados dos seus antepassados. Eram os mortos que acolhiam o recém-chegado. (GRIMAL 1984 p. 69). 
VI p. 129). Era ele o responsável pela travessia do rio Styx (7), que significava a passagem para o outro mundo das almas ou sombras dos defuntos que, conduzidas por Hermes para as profundezas da terra, teriam que atravessar o rio para chegar ao tribunal que as julgava $\left({ }^{8}\right)$. Nesta travessia participavam apenas os sepultados; os que não tiveram direito a uma sepultura não podiam atravessar o rio enquanto não "houvessem encontrado a paz do túmulo "(Eneida Livro VI pp. 129-130). Donde se pode inferir da importância da sepultura na época.

Uma vez atravessado o rio e chegados ao tribunal, o lugar de cada um é determinado pelo juiz Minos, que convoca a Assembleia dos Silenciosos e que inquire da sua vida e dos seus crimes (Eneida Livro VI p. 132). Todos quantos atravessam o rio são sujeitos ao mesmo julgamento: depois da morte reina a igualdade e os pobres verão "que os ricos aqui não estão em melhor situação, de forma alguma, do que eles" (.Diálogo dos Mortos I p. 21).

E também a dor perante a morte atingia todos de igual modo. Assim, era costume desgrenhar-se o cabelo em sinal de luto e chorar o morto levantando as mãos para o céu e batendo no peito $\left({ }^{9}\right)$.

Mas já na realização dos funerais se verificavam diferenças consoante o estatuto social e até a idade. Assim, após uma exposição do corpo de 1 a 7 dias, realizavam-se os funerais: simples e durante a noite para os pobres e crianças, durante o dia para as pessoas de melhores condições $\left({ }^{10}\right)$.

(7) Pela passagem se pagava um óbolo. Sobre este assunto é interessante 1er o diálogo XXII, da obra Diálogo dos Mortos, entre Caronte e Menipo que não tem dinheiro para pagar a passagem.

$\left.{ }^{8}\right)$ Sobre a forma como se processa a passagem do rio e a condução ao tribunal, pode ler-se o diálogo X do Diálogo dos Mortos.

$\left.{ }^{9}\right)$ "A sociedade antiga pagã considerava a expressão pública da dor como fazendo parte integrante do processo de luto e sobretudo do culto funerário: ela traduzia a crença na sobrevivência do homem na sepultura e uma vaga crença de acções nefastas da parte dos mortos que se sentem insuficientemente lastimados" (HEENE p. 165).

Este aspecto se verifica aquando dos funerais de Palante: "Ao redor do cadáver estava toda a chusma dos seguidores e a multidão troiana e as mulheres de Ilião, que, segundo o costume, tinham os cabelos desgrenhados em sinal de luto. Logo que Eneias entrou no alto portal, elas ergueram para o céu batendo no peito, grandes lamentos, e o palácio do rei ressoa com o triste pranto". \{Eneida livro XI pp. 237-238).

$\left(^{0}\right)$ Sobre os rituais fúnebres: Dictionnaire des Antiquités Grecques et Romaines, s. v. "Funus" e "Funérailles". Sobre o ritual de cremação, v. livro XI da Eneida, em que se descrevem os funerais de Palante.

Conimbriga, 35 (1996) 107-127 


\section{O DIÁLOGO ENTRE OS MORTOS E OS VIVOS}

\section{Fórmulas de saudação}

Da análise realizada, o primeiro aspecto a realçar é o facto de as formas de saudação oral - Have ou Ave, salve e vale ( ${ }^{\mathrm{n}}$ ) (comparáveis à grega chaere) - serem igualmente utilizadas nas saudações escritas e, como tal, nos epitáfios. Também nestes a dupla grafia Have/vale testemunha a diferente forma de pronunciar a palavra. O gramático Quintiliano (cit. por ALmeDA 1965 p. 108) considera mais correcta a grafia have, porque esta é uma das palavras que perderam a aspiração.

Se as saudações dos vivos nos epitáfios recolhidos são simples, resumindo-se a um modesto "Adeus e passa bem" - Ave et vale, as que os defuntos fazem são mais complexas procurando sempre especificar que se saúda quem continua a viver - valete superi (n. ${ }^{\circ}$ 6). E, de entre os vivos, o cumprimento do defunto dirige-se, naturalmente, aos que leram o seu epitáfio - Venisti ave, legisti vale (n. $\left.{ }^{\circ} 1\right)$, Tu qui legis ave, perlegisti vale (.$^{\circ} 2$ e 3 ) e lege et vale (n. ${ }^{\circ}$ ) - ou deram atenção ao seu monumento - salve hoc monumentum visitum venis vale $\left(\mathrm{n} .^{\circ} 7\right)$ e Bene sit tibi viator qui me non praeteristi (n. $\left.{ }^{\circ} 10\right)$. Mesmo nas saudações mais simples - vale (n. ${ }^{\circ}$ 9) e salvos seis $\left(\mathrm{n} .{ }^{\circ} 8\right)$ - o defunto pede ao transeunte para 1er o seu epitáfio (n. ${ }^{\circ}$ 9) dirigindo-se, portanto, a saudação unicamente a quem o faz ou dá uma resposta à saudação que lhe dirige um transeunte $\left(\mathrm{n} .{ }^{\circ} 8\right)$. Curiosa é também a situação em que o defunto saúda específicamente os viajantes -Avete vos viatores et bene valete ( $\left.\mathrm{n} .{ }^{\circ} 4\right)$, devendo, assim, o monumento estar colocado numa estrada.

Pode concluir-se, em síntese, que a saudação que parte do defunto é facilmente identificável, pois procura sempre especificar a quem se dirige o cumprimento.

\section{As saudações: um fenómeno de aculturação}

Do estudo realizado, o primeiro aspecto a referir é que este tipo de formulário aparece, na Península, em ambientes urbanos. Não em

$\mathrm{(}^{\mathrm{n})}$ Dictionnaire des Antiquités, s. v. "saudado", p. 1059. A leitura deste artigo é também interessante pela descrição de um certo número de gestos e atitudes que complementam a saudação.

Conimbriga, 35 (1996) 107-127 
cidades do interior mas, essencialmente, em cidades marítimas e fluviais.

Numa primeira abordagem, pode afirmar-se que este tipo de formulário é um elemento estranho à Península - pertence a uma cultura superior.

Toda a zona onde surgem os epitáfios com saudações está muito influenciada pelo ambiente cultural do Norte de África, não só a Tarraconense e a Bética, mas também a Lusitânia.

$\mathrm{Na}$ Lusitânia as relações com África estão testemunhadas pela presença de Lusitanos do outro lado do Mediterrâneo ou de Africanos no nosso território e pelo comércio com África: trazia-se azeite e terra sigillata de África e levavam de volta ânforas de garum (ALARCÃO 1990 p. 434). E, além disto, documentam-se alguns cognomes típicos do Norte de África no conventus Pacensis, que atestam a existência de imigrantes africanos na Península (IRCP p. 775).

O CIL regista 33 (12) exemplos de epitáfios com saudações, no Norte de África, sendo mesmo uma delas muito interessante. É o epitáfio proveniente de TiKlat, na província da Mauritânia (CIL VIII 8854): Chaere ("Bom dia!"), expressão que vem do grego, o que leva a levantar a hipótese da possível origem grega deste tipo de formulário. E, na realidade, também Bruno Lier (cit. por CAGNAT p. 286, nota 1) considera que este formulário foi traduzido do grego por eruditos, posto por eles sobre a sepultura dos parentes e copiado depois nos cemitérios por gente da cidade à procura de poesias funerárias para usar e reproduzir, fielmente ou não. A análise por mim feita em relação à Península Ibérica parece ir neste sentido, pois muitos dos epitáfios com saudações são de indivíduos de origem grega. Os Gregos entram na Península Ibérica pelo Mediterrâneo e pelo Atlântico, a partir de 750 a.C. Desta sorte, em toda a zona costeira e inclusivamente no interior - caso de Murcia e Medellin, locais onde também surgem epitáfios com saudações - se verifica a ocorrência de vasos gregos. Na Andaluzia, existem mesmo algumas produções regionais que imitam as produções helénicas (ROUILLARD pp. 113-116, 195 e 361). Tudo isto demonstra, assim, contactos que, desde cedo, se verificaram entre a Península e o mundo helénico.

(2) CIL VIII 440, 2029, 2841, 4256, 4570, 4574, 5030, 5260, 5261, 5370, 5502, 7741, 8854, 9069, 9158, 9164, 9728, 11257, 11283, 11520, 11549, 11597, 12924, 14697, 15724, 16013, 17961, 19146, 20394, 20875, 21179, 21284, 21541.

Conimbriga, 35 (1996) 107-127 
Os dois maiores núcleos onde surgem epitáfios com saudações são a ilha de Maiorca, nas Baleares, e Cartagena.

De Maiorca são provenientes dezoito epitáfios com saudações ao defunto, quinze deles do povoado romano de Santañy.

As Baleares, pela sua situação geográfica, foram escala obrigatória de migrações indoeuropeias, estando, a partir do séc. VII a. C., em relação com os navegantes fenícios e gregos. Aliás, frequentemente, os habitantes destas ilhas integraram exércitos gregos, púnicos ou romanos, como mercenários. Roma conquistou-as em 123 a. C. (MANGAS 1980 pp. 187-189).

Aqui a saudação nos epitáfios é muito comum, daí aparecer muitas vezes abreviada $\left({ }^{13}\right)$. Todas estas saudações se dirigem ao defunto. Surgem em epitáfios de indivíduos que, geralmente, se identificam com os tria nomina, parecendo fora de dúvida o carácter indígena desses nomes (14) (ALBERTOS 1958 p. 236), à excepção de um liberto, Quintus Sergius Demophon (CIL II 3693), cujo cognome denuncia origem grega. São pequenas placas de xisto, provavelmente para colocar nos columbaria, à excepção de dois cipos (EE IX 358 e CIL II 3672), que devem poder datar-se do séc. I d. C, pelo tipo de formulário bastante simples e pela ausência de consagração aos deuses Manes que apenas aparece num exemplar (CIL II 3686).

A existência de quase uma vintena de epitáfios com saudações praticamente iguais, em Maiorca, pode apontar para a hipótese de ser um formulário que o lapicida tinha entre mãos.

Onde esta hipótese também poderá ser válida é em Cartagena, onde surge o maior número de epitáfios com saudações na Península, incluindo não só saudações ao defunto, mas também deste aos vivos.

Cartagena foi uma cidade fundada por Asdrúbal (genro de Amílcar Barca que havia desembarcado na Hispânia na cidade de Gades, em 237 a.C.), de crucial importância por constituir o centro coordenador da exploração das minas de prata da região (MATTOso p. 208).

Com a exploração das minas deve estar relacionado o facto de, entre os vinte e cinco epitáfios com saudações, a maior parte deles ser de libertos. Assim, os dois epitáfios com saudações do defunto são um

(13) CIL II 3672, 3677, 3679, 3680 e EE IX 359.

${ }^{(14)}$ Há, na antroponimica baleárica, vestígios das migrações indoeuropeias e mediterrânica: é o caso do cognome $P$ aditu (CIL II 3830) (cfr. Albertos 1958). É este o cognome de um indivíduo que tem epitáfio com saudação. 
de uma liberta - Plotia Phyrne (n. $\left.{ }^{\circ} 8\right)$ - cujo cognome denuncia a origem grega, e outro muito provavelmente de uma escrava (n. ${ }^{\circ}$ 7) pois só se identifica com um nome - Cila. Dos epitáfios com saudação ao defunto (que são vinte e três) quinze são de libertos que se identificam como tal (15) ou cujo estatuto se denuncia pelo cognome grego Lucius Argentarius Nicander (AE 1987 658) e Numisia Philematio (CIL II 3488). Antigo escravo da gens dos Numisii, gens importante em Cartagena no início do Império (AE 1987 p. 186), seria igualmente Cn(aeus) Numisius Epigonus (AE 1987 659).

Verifica-se também uma relação familiar nos patronos de Lucius Fufius Varus (CIL II 3465) e de Plotia Phyrne (n. ${ }^{\circ}$ 8). O patrono do primeiro seria, com certeza, da famñia da patrona — Fufia — da segunda, que, como já referi, é de origem grega.

Libertos de origem grega que viveram em Cartagena e tiveram um epitáfio com saudação foram, ainda, Publius Lollius Philemo (CIL II 3476), Lucius Vinuleius Philogenes (BELTRÁN 1950 112) e Octavia Calliopa (CIL II 3490).

Com cognome grego temos ainda Statia Scat(imia) Phila (CIL II 5933, BELtrÁN 1950 92, Iler 3816), que se identifica com dois gentilicios e filiação. A presença dos dois gentilicios leva-me a pensar que terá sido adoptada.

Estes epitáfios de Cartagena também se podem datar, pela simplicidade do formulário, do séc. I d. C.

Junto a Cartagena, em Murcia, detectei ainda um epitáfio com saudação à defunta, tratando-se de mais uma liberta: Lucretia (CIL II 3540).

A seguir a Cartagena e à ilha de Maiorca, o maior núcleo com saudações é o de Tarragona, que desde cedo conhece a presença romana — em 270 a. C., Augusto fixa-se em Tarragona (ALARCÃO 1973 p. 48). Aqui se encontraram oito epitáfios com saudação, sendo apenas um com saudação do defunto (n. $\left.{ }^{\circ} 10\right)$. Este seria quiçá originário de Samotrácia, verificando-se, mais uma vez, a origem grega dos indivíduos com saudações nos seus epitáfios.

De Tarragona provêm ainda sete epitáfios com saudação aos defuntos:

- É o epitáfio de Plotia Saturnina (BATTLE 101, ILER 3808), que lhe é dedicado pelo marido - Aelius Mepon — e pela filha, Plotia

(15) CIL II 3465, 3476, 3478, 3490, 3492, 3506, 3507, 3511, 3512, HAEp 121, BELTRÁN 1950 112, AE 1977 457, e EE 343. 
Iucunda. $\mathrm{O}$ facto de a filha se identificar com o gentilicio da mãe e o facto de o pai ter cognome grego é porque este se trataria, com certeza, de um antigo escravo;

- O epitáfio que a ama Trepte dedica à criança de 8 meses de que cuidava (HAEp 1492, MANGAS p. 188): o nome da ama é também de origem grega.

- Outro é o de Volusia Paterna (CIL II 4419).

- O epitáfio com a saudação a Caecilia Doris (CIL II 4290, RIT 408), do seu marido, Lucius Lucretius Martinus, um dos sêxviros locais.

- O epitáfio, muito provavelmente de um escravo, pois se identifica só com um nome grego, Alethi (CIL 4330, ILER 3803).

- O de Aphrodite (CIL 4445, MANGAS p. 190, ILER 3806, RIT 910) que, pela utilização de um so nome e de origem grega, terá sido com certeza uma escrava.

- E, por último, o epitáfio com uma saudação a Fabia Festa (ILER 3837).

Aqui, a hipótese de ser um formulário característico de uma oficina já é mais remota, uma vez que o tipo de saudação não é igual em todos os epitáfios - Bene sit tibi viator qui me non praeteristi (n. ${ }^{\circ}$ 10), Ave Fabius Festus te salutat (CIL II 3837), Have (CIL 4419, 4445, 4290 e ILER 3808), Have et vale (HAEp 1492), Ave (CIL II 4330) - e, sendo característica de uma oficina, seria mais logico que o formulàrio fosse semelhante, como em Maiorca ou Cartagena.

Entre Cartagena e Tarragona situa-se Sagunto, cidade também costeira e de onde provêm dois epitáfios com saudações. Um deles contém uma saudação do defunto, um magistrado, sendo todo o epitáfio bastante poético e denotando algum nível cultural por parte de quem o encomendou (n. ${ }^{\circ}$ 9). O epitáfio com saudação dos vivos é o epitáfio de Lucius Valerius Supertestes (?), de 4 anos, de Valeria Maure (?), de 12 anos, e de Valeria Amoena, de 25 anos (CIL II3942), muito provavelmente irmãos. A presença de epitáfios com este tipo de formulário neste local não é de estranhar, pela proximidade quer das Baleares, quer de Tarragona e de Cartagena. Já o mesmo não acontece em Albarracín que, situando-se no interior, está bastante afastada da costa e, portanto, das cidades citadas. Aqui, a defunta é saudada (CIL 3178), sendo muito provavelmente escrava, uma vez que só se identifica com um nome - Procle — de origem grega.

Seguindo a linha costeira, em Cádis, voltamos a encontrar mais quatro epitáfios com saudações. Três com saudações ao defunto e um 
com saudação ao defunto e deste aos vivos (n. ${ }^{\circ}$ 6). Este epitáfio, de uma indígena romanizada, contém assim uma saudação recíproca entre vivos e mortos. Quanto aos outros:

- É o epitáfio de Annia Saturia (CIL II 1759, ILER 3807) cujo gentilicio se documenta um pouco por toda a parte no Sul de Portugal (IRCP p. 526). A utilização de onomástica latina, omitindo o parentesco, indica tratar-se de uma indígena romanizada.

- O outro epitáfio é o de Publicia Fortunata (CIL II 1871, ILER 3809), cujo gentilicio denuncia a sua origem escrava, pois Publicius é um gentilicio característico dos libertos públicos duma cidade ou colónia (IRCP p. 58, 136 e 169). Por outro lado, o cognome Fortunata também vai neste sentido, dado que é um nome típico desse grupo social, nomeadamente em África (KAJANTO p. 273, IRCP p. 499) e aparecendo este em Cádis não é de estranhar, dada a proximidade do Norte de África.

- O outro epitáfio (EE IX 236) está bastante fragmentado, apenas se conseguindo 1er com certeza o Ave inicial.

$\mathrm{Na}$ Bética, encontraram-se mais quatro epitáfios com saudação, em cidades das margens do Guadalquivir, dois em Itálica e um em Ilipa; e, na margem esquerda do Guadiana, um em Medellin.

Os três primeiros epitáfios são de libertos. Em Itálica, encontrou-se o epitáfio de Lucius Feronius Lucii libertus, que é saudado pelos vivos (CIL II 6279), e daqui é também proveniente o epitáfio de Quintus Heraus ?), Auli libertus (CIL II 1151). O de Ilipa é de Attenia Anna, também liberta (CIL II 1092, ILER 3804, MANGAS p. 434) e também saudada pelos vivos. A ocorrência deste tipo de epitáfios em Itálica estará, com certeza, ligada à presença grega na cidade que se intensifica com Adriano, profundamente enamorado da cultura grega (BLÁZQUEZ pp. 102-104). A proximidade de Ilipa de Itálica pode explicar a presença naquela de epitáfios com saudações. Por outro lado, sendo Ilipa uma cidade indígena privilegiada com o estatuto municipal devia reunir uma série de condições - como urbanização, presença de um grupo de cidadãos romanos no seu interior, desenvolvimento de propriedade privada (Millan p. 104) - que levariam ao emprego de mão-de-obra escrava (daí, a presença de um liberto).

Ainda na Bética, temos o epitáfio proveniente de Medellin com a saudação de uma defunta perfeitamente romanizada. Esta cidade é uma fundação colonial de Metellus, ainda que o título de colónia só lhe seja concedido com César, situando-se bastante próximo da Lusitânia - 
onde também se encontram epitáfios com saudação - nomeadamente da sua capital, Mérida, com a qual comunicava por uma via que atravessava o rio ali mesmo (GARCÍA Y BELLIDO p. 14).

As produções da Lusitânia poderiam ser transportadas para o porto bético de Cádis e outros do litoral mediterrânico da Península Ibérica; carregadas em pequenas embarcações, seriam aí transferidas para navios de maior tonelagem (ALARCÃO 1990 p. 433). Havendo contactos entre esta região e toda a costa mediterrânica, também é normal que surjam aqui epitáfios com saudações.

Começo por Olisipo, onde existiam já numerosos cidadãos fixados desde longa data (ALARCÃO 1990 p. 374) e que foi um dos portos principais do litoral atlântico (ALARCÃO 1990 p. 432) — o que levou a que esta cidade também estivesse em contacto com muitas populações. O epitáfio de Lisboa é de Passeria Romula (AlmeIda 1965 VII, ILER 3810), de 4 anos, saudada pelos vivos. Passerius é um nomen do qual só encontrei este exemplo na Península (16) e que — por simples coincidência? — é igual ao de um indivíduo de certa importância que desempenhou funções públicas na região de Mileto (Jónia): Lucius Passerius Romulus (CIL III 7150).

Em Ourém, no vale do Nabão, encontrou-se outro epitáfio com saudação, mas desta vez do defunto (n. $\left.{ }^{\circ} 1\right)$ : é o epitáfio de Pristinus, um indígena recém-romanizado. Este epitáfio foi encontrado no local onde parece ter existido uma povoação romana (COSTA 1983 p. 7). Há que ter em conta a proximidade de Olisipo onde, como já referi, se estabeleciam contactos com pessoas oriundas de muitos locais. E também há que não esquecer Sellium: "decerto que as duas cidades estariam ligadas por uma estrada que quase necessariamente teria de passar no concelho de Ourém, isto porque uma recta a ligar as duas cidades iria mesmo cair no alto da Serra d'Aire" (BERNARDES, p. 91).

No vale do Tejo, em Cáceres, surge mais um exemplo de epitáfio com saudação do defunto (n. $\left.{ }^{\circ} 4\right)$. É o epitáfio de uma indígena que conhece bem os hábitos culturais romanos.

Um pouco mais acima, em Idanha-a-Velha, capital da Civitas Igaeditanorum, encontraram-se dois epitáfios com saudações do defunto (n. ${ }^{\circ} 2$ e 3), sendo o formulário igual: tu qui legis ave, perlegisti vale. Este aspecto, juntamente com a semelhança de nomes - Rufinus Rufi f(ilius) e Ceionius Rufinifiilius) — leva-me a pensar numa possível ligação familiar entre os dois defuntos, indígenas romanizados.

(16) O CIL não regista nenhum exemplo e o ILER só regista este. 
Ainda na Lusitânia se detectou mais um epitáfio com saudação dos vivos. É proveniente de Mérida, cidade fundada em 25 a.C. (ALARCÃO 1990 p. 350). Urna ara que lulius Claudius e Mia dedicam à filha indulgentissima (ILER 3836).

Estes epitáfios, que surgem quase isolados, não podem ser característicos duma oficina, pois, se tal fosse o caso, por exemplo em Idanha-a-Velha, onde as inscrições ultrapassam as duas centenas, teriam que ter aparecido mais com saudações.

Relativamente à questão: — “estará este tipo de formulário ligado a alguma tipologia?" - não posso adiantar nada, uma vez que não consegui determinar a tipologia de todos os epitáfios estudados, à excepção das placas das Baleares e de uma de Cartagena (AE 1987 659) e de um ou outro caso isolado de cipos (CIL II 3672, CIL II 5773, EE IX 358, CIL 1151), de aras (CIL II 4445 e ILER 3836) e de uma estela (AE 1977 457). No entanto, penso que este tipo de formulário não se pode relacionar com nenhuma tipologia em particular.

Cronologicamente, trata-se de um fenómeno característico do séc. I e princípio do II d.C.

Em síntese, pode dizer-se que a utilização deste tipo de formulário na Península Ibérica é o resultado da aculturação de elementos estranhos à Península. Está essencialmente ligado a populações de origem grega ou indígenas romanizados (e, portanto, imbuídos de hábitos culturais romanos) que vivem em ambientes urbanos, verificando-se, mais uma vez, a importância da cidade como factor de assimilação (MANTAS 433). Estas saudações denunciam um ambiente cultural evoluído; mas se, em alguns locais, se tornaram moda (como nas Baleares), essa não foi a regra, tendo sido um formulário pouco divulgado na Península. ${ }^{3}$

\section{Modo de pensar subjacente a estas saudações:}

Estas saudações enquadram-se no diálogo que se estabelecia entre mortos e vivos, nos cemitérios romanos, situados ao longo dos caminhos afastados das cidades.

$\mathrm{Na}$ razão de ser deste diálogo estará, com certeza, uma determinada concepção de vida e uma determinada atitude perante a morte. Subjacentes à concepção de vida entre os Romanos estavam o Estoicismo e o Epicurismo: o homem podia encontrar em si mesmo as condições para ser feliz. 
Enquanto, porém, o Estoicismo considerava o saber, uma vida honesta e útil como condições necessárias para se alcançar a felicidade, o Epicurismo identificava essa felicidade com o prazer (PEREIRA pp. 96-113 e CAESSA). E que prazer? O da bebida, da comida, dos banhos, do amor $\left({ }^{17}\right)$... Eis a verdadeira vida, que se deve aproveitar, porque depois... não se sabe!

Todos estes prazeres a que estava associada a vida criavam, como é óbvio, um certo pessimismo e repugnância pela morte, apesar de manterem sempre uma esperança na continuação da vida. Mas o medo e o desconhecimento dominavam; daí que seja o próprio defunto a alertar da inevitabilidade da morte e a aconselhar que se aproveite a vida ao máximo, pois a morte summa est severitas $\left.i^{1 *}\right)$.

São vários os exemplos de epitáfios que têm patente esta filosofia epicurista. Veja-se o caso da escrava Romana (CIL II $1877=$ ILER 3800), de Cádis, que, tendo morrido aos 20 anos, pede aos transeuntes que bebam e gozem antes de morrer - T(e) R(ogo) P(raeteriens) es bibe, lude, veni, ou o de Tibério Cláudio Segundo (MAZZOLANTI CVI), de Roma, que considera que, apesar de o banho, o vinho e o amor corromperem o corpo, são eles que fazem a vida - Balnea Vina Venus corrumpunt corpora nostra, sed vitam faciunt b(alnea) v(ina) V(enus)। ou, ainda, o de Gaio Domicio Primo (MAZZOLANTI XLIX), de Ostia, que não deixa de referir que os banhos, o vinho e o amor o acompanharam até à velhice — balnia vina Venus mecum senuere per annos.

Consideravam os Romanos que, com a morte, se perdia a vida e a possibilidade de desfrutar dos seus prazeres; daí, a necessidade de o morto continuar a participar da vida - era urna forma de diminuir esse sentimento de repugnância e de receio pela morte. E a saudação era uma das formas de o morto continuar a partilhar esse saudoso mundo dos vivos. Se o morto permanecia vivo de alguma forma, era naturai que um hábito do dia-a-dia se mantivesse após a morte e com a vantagem de que, depois, todos são iguais, recebendo e dando todos a mesma saudação independentemente do estatuto social. E esta insistência em partilhar o mundo dos vivos era tão forte que Aurélio Elio (AE 1987

(,7) Sobre este assunto ver, por exemplo, a obra de CARCOPINO citada na bibliografia, especialmente a $2^{\text {a }}$ parte.

(18) Advertência dada no epitáfio de Gneu Cornélio Basso, de Roma (Mazzolani XI). 
125), de Roma, ordena mesmo a quem não o saudou que o faça: Et tu qui me non salutasti vene valetol

Com o advento do Cristianismo, há uma mudança na concepção da vida e morte. A morte passa a ser encarada como um dies natalis e não como um ponto final (HeENE p. 177). Passa a ser a esperança, a libertação e a recompensa da vida, a passagem para a eternidade. Os mortos deixam de meter medo aos vivos, aproximam-se deles (CAESSA p. 21) - daí, a presença dos cemitérios dentro das cidades. Relacionado com esta mudança está o facto de este tipo de epitáfios com advertências, conselhos e saudações ir desaparecendo.

Houve, de facto, mudança na concepção da vida e na atitude perante a morte. Apesar disso, quão próximo não estará o nosso pensamento, ou o da maior parte de nós, do de Romana, de Tibério Cláudio Segundo ou de Gaio Domício Primo!

Quantas vezes não pensamos "A vida é curta, temos é que aproveitar enquanto cá andamos". Tão longe no tempo, próximos nos sentimentos!

\section{CATÁlOGo}

\section{Inscrição $n .^{\circ} 1$}

Ach: Freguesia de Rio de Couros, Ourém.

Par: $\quad$ Mantém-se na posse do achador.

$D$ \{ iis)-M(anibus) [S \{acrum) \/ PRISCINO / PRISCI $\cdot F$ (ilio) / CONTV $\mathrm{BE} / \mathrm{s} \mathrm{RNALES} / \mathbf{F}($ aciendum $) \cdot \mathrm{C}($ uraverunt $) \cdot \mathrm{S}($ it $) \bullet \mathrm{T}($ ibi $) \bullet \mathrm{T}($ erra $) \bullet \mathrm{L}\{$ evis $)$ / VENISTI/ AVE / LEGISTI /10 VALE

AE 1984, 477; FE 8, 34.

\section{Inscrição n. ${ }^{\circ} 2$}

Ach: Idanha-a-Velha, Idanha-a-Nova.

Par: $\mathrm{Na}$ "catedral" de Idanha-a-Velha (Foto

2).

RVFINVS (hedera) RVFI / F (ilius) (hedera) ANN (orum) \{hedera) $\mathrm{XXV}$ (viginti quinque) \{hedera) $\mathrm{H}(/ \mathrm{c}) \mathrm{S}$ \{itus) $\mathrm{ES}[\mathrm{T}] / \mathrm{TV}$ \{hedera) QVI LEGIS \{hedera) AVE / PERLEGISTI VALE

Egitânia 117. HAEp. 1158. LAMBRINO 38. ILER 3834.

\section{Inscrição n. $^{\circ} 3$}

Ach: Idanha-a-Velha, Idanha-a-Nova

Par: $\mathrm{Na}$ "catedral" de Idanha-a-Velha (Foto 
CEIONIVS - RVFINI - F(ilius) / $\mathrm{AN}($ norum) $\cdot \mathrm{XXV}$ (viginti quinque) $\mathrm{H}(/ \mathrm{c}) \mathrm{S}($ itus $) \mathrm{E}($ st) $\mathrm{S}($ it) $\bullet \mathrm{T}($ ibi $) \bullet \mathrm{T}($ erra $) \bullet L(e v i s) / \mathrm{TV} \bullet \mathrm{QVI} \bullet \mathrm{LEGIS} \bullet \mathrm{AVE} \bullet$ QVI / PERLEGISTI. VALE

Egitânia 57. HAEp. 1018. LAMBRINO 19. ILER 3835.

\section{Inscrição n. ${ }^{\circ} 4$}

Ach:

Torre de D. Miguel, Cáceres

Par: ?

LVNI. TAPI/LI. F(i7//). CIPVS [sic] / STATVIT . TA/PILVS ET /5 TRITIVS LVNI FILI / ET. CATVR/O ALBONI / ET MACE/10NVS. ARENI / AVETE. VOS / VIATO/RES • ET. B/ENE. VALLETE

CIL II 5304. ILER 3840. CPIL 496.

\section{Inscrição n. ${ }^{\circ} 5$}

Ach:

Medellin.

Par: ?

[G]RAECIA (?) / MODESTA / HEIC. SITA [EST] SIT. TIBI. TERR/5A • LEVIS • LEG/[E ET]»VALE / L (ocus) $¥\{$ edum) XII \{duodecim).

CIL II 611. ILER 3831.

\section{Inscrição n. ${ }^{\circ} 6$}

Ach:

Cádis.

Par: Desaparecida.

AVE / HERENNIA. CROCINE / CARA. SVEIS . INCLVSA. HOC • TVMVLO / CROCINE. CARA SVEIS . VIXI. EGO /5 ET ANTE. ALIAE. VIXERE . PVELlAE / IAM . SATIS . EST . LECTOR . DISCENDENS / DICAT. CROCINE. SIT. TIBI. TERRA / LEVIS. VALETE. SVPERI

CIL II 1821. BATTLE 79. ILER 3812a e 5804. GONZÁLEZ 217. MAZZOLANI L.

\section{Inscrição n. ${ }^{\circ} 7$}

Ach:

Cartagena. Encontrada numa casa privada, na rua del Aire, onde actualmente se encontra o Grande Hotel.

Par: Desaparecida.

Lápide de calcário.

Dimensões: $40 \times 25 \times 17$

CILA . SALVE ET VALE / SALVE HOC MONVMENTVM / VISITVM [ SiC] VENIS / VALE.

BELTRÁN 1949 p. 532. BELTRÁN 1950 26. HAEp. 61. 


\section{Inscrição n. ${ }^{\circ} 8$}

Ach:

Cartagena (ignora-se a sua procedência exacta).

Par:

Uma parte conserva-se no Museu Arqueológico Nacional de Madrid (A) e outra parte, menor, no Museu de Cartagena (B).

PLOTIA . L (ucii) • ET FVFIAE . Libertà) • PHRYNE HAEC •

$\operatorname{VOC}(/) / T A T A(e) S T \cdot A N C I L L A$. HEIC. SITA $(e) S T \cdot$ HAEC / QVALIS .

FVERIT . CONTRA. PATRONVM . PATRO/NAM . PARENTEM .

CONIVGEM. MONVMEN/5TVM. INDICAT. SALVE. SALVOS • SEIS. [sic]

CIL II 3495. BELTRÁN 195078.

\section{Inscrição n. ${ }^{\circ} 9$}

Ach:

Puzol, Sagunto.

Par:

Desaparecida.

[VALE]RIVS• $h$ (ucii) F(ilius) MAR/[...]VS. AN(norum) XXIX (yiginti

novem) / H(/c) S (itus) E (st) / [LEGE VIAT]OR FLE CASVM MEV[M] /[...]

VS $[\ldots / 5 . ..] \mathrm{S}$ AEDIL[I]S DIEB VS $/[\ldots]$ XXX (/triginta) DE [......] [MO]RS

RAPVIT ET TV/[MVLA]VI[T] AMOR / VALE

BELTRÁN LLORIS 284.

\section{Inscrição $n .^{\circ} 10$}

Ach:

Tarragona.

Par: Desaparecida.

$\mathrm{D}$ (iis)-M(anibus) / BENE.SIT-TIBI-VIATOR / QVI ME NON PRAETE/RISTI LEGE HOC PAVS[AN]S [sic] HIC /5IACEO - SAMIISTRIARIA / NATVS VI(JU) ANN(w) IV (quatuor) MEI / SI QVIT SVPERV HIC ME / SOLEVS NEMINI [...]DEBET.

CIL II 4174. ILER 5815. RIT 696.

\section{BIBLIOGRAFIA}

AlARCão (Jorge de), Portugal Romano, Lisboa, 1973 (= ALARCão 1973). et alii, Nova História de Portugal, vol. I, Lisboa, 1990 (= ALARCão 1990).

ALbertos (Maria de Lourdes), "Indoeuropeus o iberos en Baleares", Emerita, Tomo XXVI, fase. $2^{\circ}, 1958$, pp. 235-240 (= ALBERTOS 1958).

La Onomastica Personal Primitiva de Hispania Tarraconense y Betica, Salamanca, 1966 (= ALBERTOS 1966).

"La Antroponimia Prerromana en la Peninsula Iberica", Actas del I Coloquio sobre Lenguas y Culturas Prerromanas de la Peninsula Iberica (1974), Salamanca, 1976, pp. 57-86 (= ALBERTOS 1976).

ALFoldy (Géza), Die Römischen Inschriften von Tarraco (= RIT), Berlim, 1975. 
Almeida (D. Fernando de), Egitânia. História e Arqueologia, Lisboa, 1956 (=Egitânia).

Almeida (Justino Mendes de) e Ferreira (Fernando Bandeira), "Varia Epigraphica (Nova Série)", Revista de Guimarães, voi LXXV, 1965, pp. 105-109 (= ALMEIDA 1965).

- L Année Épigraphique (=AE), Paris, 1977, 1984, e 1987.

ARIÈs (Philippe), O Homem perante a Morte, I, 1977 (= ARIÈs).

Battle Huguet (Pedro), Epigrafia Latina, Barcelona, ${ }^{2} 1963$ (= BATTLE).

BELTRÁn (António), "Las inscripciones latinas honorarias de Cartagena", Revista de Archivos, Bibliotecas y Museos, t. LV, n. ${ }^{\circ}$ 3, 1949, pp. 523-547 (=BELTRÁn 1949). "Las inscripciones funerárias en Cartagena", Archivo Español de Arqueologia, t. XXIII, n..$^{\circ}$ 81, 1950, pp. 385-433 (= BELTRÁN 1950).

Beltrán Lloris (F.), Epigrafia Latina de Saguntum y su Territorium, Valencia, 1980 (= BELTRÁN LLORIS).

Bernardes (João Pedro), Subsídios para a Carta Arqueológica do Concelho de Vila Nova de Ourém, Instituto de Arqueologia da Faculdade de Letras de Coimbra, 1985 (= BERNARDES) (dactilografado).

BLÁzqueZ (J. M.), "Una ciudad bética de agricultores: la Itàlica de Hadriano", La Città Antica come Fato di Cultura, Atti del Convegno di Como e Bellagio (1979), Como, 1983, pp. 93-104 (= BLÁZqUEZ).

BLOCH (Raymond), L'Épigraphie Latine, Paris, 1964.

CAEssa (Ana Isabel de Sá), "Viver docemente e descansar em paz!", Jornal de Coimbra, 27-07-88, p. 21 (= CAESSA).

Cagnat (René), Cours d'Épigraphie Latine, Paris, ${ }^{4} 1914$ (= Cagnat).

Carcopino (Jerome), A Vida Quotidiana em Roma no Apogeu do Impèrio, Paris, 1939. CIL: cf. Hübner.

COSTA (João), "Inscrição funerária de Vila Nova de Ourém", Ficheiro Epigráfico (=FE) 8, n. ${ }^{\circ} 34,1984$, pp. 13-16.

Epigrafia romana do concelho de Vila Nova de Ourém, Instituto de Arqueologia da Faculdade de Letras de Coimbra, 1983 (= CosTA 1983) (dactilografado).

CPIL: cf. HURTADO DE SAN ANTONIO.

Daremberg (Ch), Saglio (E.), Pottier (E.), Dictionnaire des Antiquités Grecques et Romaines, Paris, 1877, s. v. "funus", funérailles" e "saudatio" (= Dictionnaire des Antiquités).

- Egitânia: cf. AlmeIdA.

EnCARnaÇão (José d'), Sociedade Romana e Epigrafia, Setúbal, 1979.

"Epigrafia: uma leitura diferente", Munda, n. ${ }^{\circ}$ 7, 1984, pp. 31-34.

Inscrições Romanas do Conventus Pacensis (=IRCP), Coimbra, 1984.

"Indigenismo e romanização na Lusitânia", Biblos, vol. LXII, 1986, pp. 451-464.

Introdução ao Estudo da Epigrafia Latina, Coimbra, 1987.

"Venisti, Ave! Legisti, Salve!”, Lions Portugal, n. ${ }^{\circ}$ 5, 1987.

ETIENNE (Robert), Recensão a J. Mangas, Esclavos y Libertos en La España Romana, in Archivo Español de Arqueologia, vol. 49, 1976, pp. 211-224.

FABRE (G.) et LÉVÊQUe (Pierre et Monique), Fouilles de Conimbriga II - Épigraphie et Sculpture (= Fouilles II), Paris, 1976. 
FOrCELlinI (Aegidio), Lexicon Totius Latinitatis, Pádua, 1940 (= FORCELLINI).

GARCía Y BELLIDO (A.) "Las colonias romanas de la provinvia Lusitania", Arqueologia e Historia, $8^{\text {a }}$ série, voi. Vili, 1958, pp. 11-23.

GonzÁlez (J.), Inscripciones Romanas de la Provincia de Cádiz, 1982, (= GonzÁLEz).

Grimal (Pierre), A Civilização Romana, Lisboa, 1988 (= GrimaL).

HeEne (Katrien), "La manifestation sociale de l'expérience du chagrin: Le témoignage de la poésie épigraphique latine", Epigraphica, L, 1988, pp. 163-177 (= HEENE).

- Hispania Antiqua Epigraphica (=HAEp.), 1-3, Madrid, 1950-1952; 6-7, Madrid, 1955-1956; 8-11, Madrid, 1957-1960.

- Hispania Epigraphica (=HEp), Madrid, n. ${ }^{\circ}$ 1, 1989; n. ${ }^{\circ} 2,1990$.

HüBNER (E.), Corpus Inscriptionum Latinarum - II (=CIL II), Berlim, 1869, 1892 (suplemento).

Corpus Inscriptionum Latinarum - Vili (=CIL Vili), Berlim, 1881.

Ephemeris Epigraphica (=EE), vol IX, Fase. 1, 1913.

Hurtado de San Antonio (Ricardo), Corpus Provinvial de Inscripciones Latinas (Cáceres), Cáceres, 1977 (=CPIL).

ILER $=$ cf. VIVES.

Jiménez de Cisneros Hervás (Diego), "Nuevas inscripciones romanas de Cartagena", Boletín de la Real Academia de la Historia (=BRAH), T. XCVI, vol. I, 1930, pp. 248-255.

KAJANTO (Iiro), The Latin cognomina, Roma, ${ }^{2} 1982$ (= KAJANTO).

LAMBRINO (Scarlat), "Les inscriptions latines inédites du Musée Leite de Vasconcelos", O Arqueólogo Português, n. s. III, 3-4, 1956, pp. 5-73 (= LAMBRINO).

LAVAGNE (Henri), "Le tombeau, mémoire du mort", La Mort, les Morts et T Au-Delà dans le Monde Romain, Actes du Colloque de Caen 20-22 Nov. 1985, pp. 159-165.

LUCIANO, Diálogo dos Mortos — Trad, de Américo da Costa Ramalho, Coimbra, 1989.

MANGas ManJARRES (Julio), Esclavos y Libertos em la España Romana, Salamanca, 1971 (= MANGAS 1971).

TuÑON de LARa (Manuel) e TARRadell (Miguel), Historia de España, I, Barcelona, 1980 (= MANGAS 1980).

Mantas (V. Gil), "Orarium donavit Igaiditanis: epigrafia e funções urbanas numa

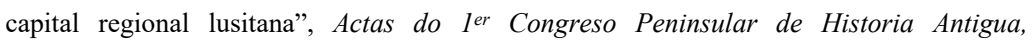
Santiago de Compostela, 1988, pp. 419-439.

Mattoso (José) et alii, História de Portugal, vol. I, Lisboa, 1992 (= Matroso).

MaUleOn (M Dolores), indices de las Inscripciones Latinas Publicadas en el Boletín de la Real Academia de la Historia (1877-1950), Pamplona, 1983.

Mazzolani (Lidia Storoni), Iscrizioni Funerarie Romane, Milão, 1991 (= MAZzolani).

Millan LeON (José), Ilipa Magna, Alcalá del Rio, 1989 (= Millan).

Pereira (Ma Helena da Rocha), Estudos de História da Cultura Clássica, II, Lisboa, ${ }^{2}$ 1990.

Petrónio, O Satiricon, trad, de Jorge de Sampaio, Lisboa, 1973.

Rodríguez Adrados (Jesús), "Anotaciones a CIL II 3511", Emérita, T. XXXVIII, Fase. $.^{\circ}, 1970$, pp. 325-326 (= RoDRíGUEZ 1970).

Conimbriga, 35 (1996) 107-127 
Rodríguez Neila (J. F.), "Espacios de uso funerario con indicación de medidas en las necropolis romanas", Conimbriga, XXX, 1991, pp. $59-94$ (= RoDRíGUEZ 1991).

RouILlaRd (Pierre), Les Grecs et la Péninsule Ibérique du VIIIe au IVe siècles avant Jésus-Christ, Paris, 1991 (RouILLARD).

SUSINI (G. C.), Epigrafia Romana, Roma, 1982.

Untermann (Jürgen), Elementos de um Atlas Antroponimico de la Hispania Antigua, Madrid, 1965 (= UNTERMANN).

VASCONCELOS (J. Leite de), Religiões da Lusitânia, Lisboa, voi. Ill, 1913.

Veny (C.), Corpus de las Inscripciones Balearicas Hasta la Dominación Arabe, Roma, 1965 (= VENY).

VERGÍLIO, Eneida, Trad, espanhola de Miguel Querol, Barcelona, 1979 (=Eneida).

VeYNe (Paul), "O Impèrio Romano", História da Vida Privada, I, Porto, 1989, pp. 19-224.

VIVES (J.), Inscripciones Latinas de la España Romana, Barcelona, 1971 e 1972 (índices) (= ILER). 


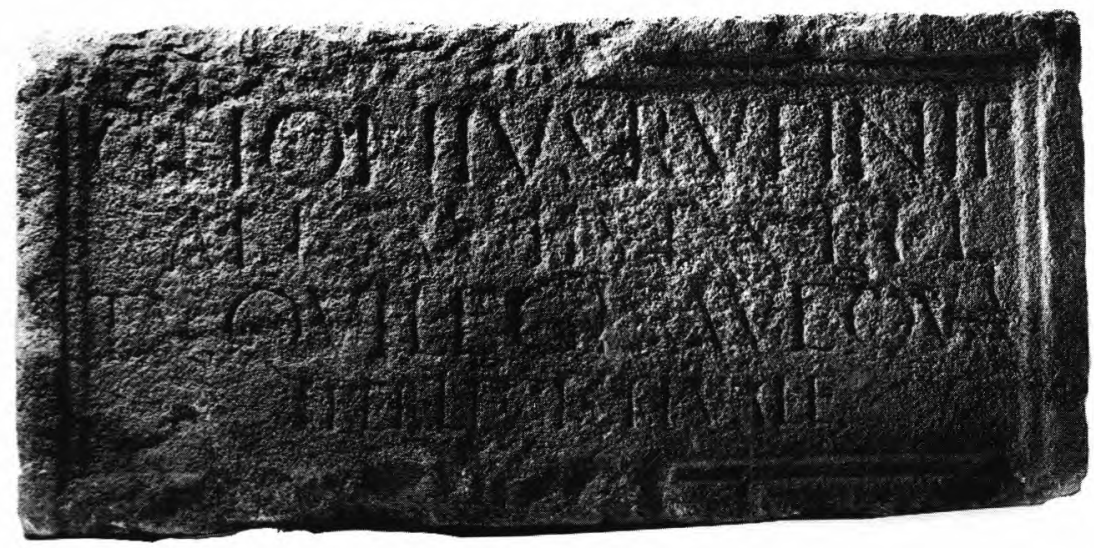

Foто 1

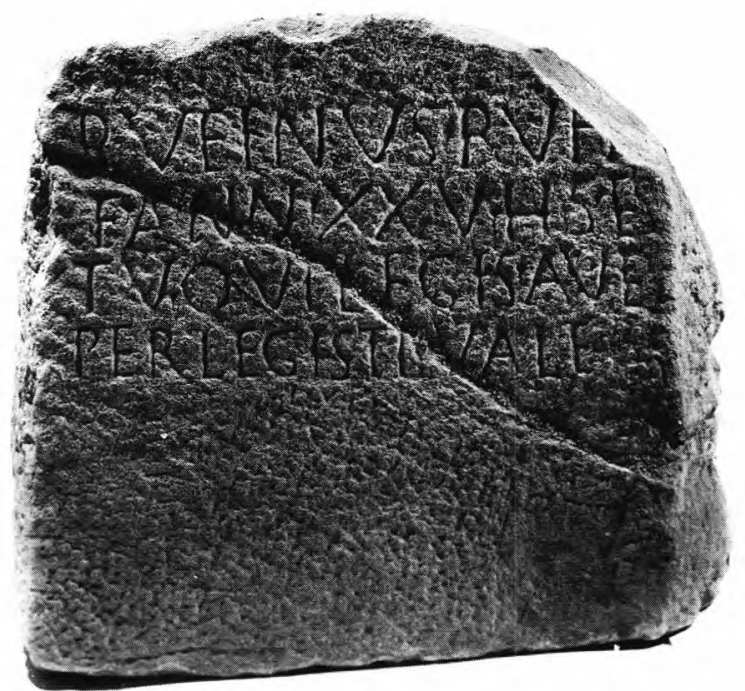

Fото 2 